\title{
The good, the bad, and the ugly of environmental quality benchmarks: EQSPAE-2016 dedicated to Dr. Peter Michael Chapman (1951-2017)
}

\author{
Kenneth M. Y. Leung ${ }^{1} \cdot$ Graham Merrington $^{2} \cdot$ Michael St. J. Warne ${ }^{3} \cdot$ Richard J. Wenning ${ }^{4} \cdot{\text { Fengchang } \mathbf{W u}^{5}}^{5}$
}

Received: 8 December 2017 / Accepted: 13 December 2017 / Published online: 3 January 2018

(C) Springer-Verlag GmbH Germany, part of Springer Nature 2017

The inaugural International Conference on Deriving Environmental Quality Standards for the Protection of Aquatic Ecosystems (EQSPAE-2011) was held at the University of Hong Kong (HKU), Hong Kong, China, in December 2011. The proceedings of this first conference dedicated to improving methodologies for setting environmental quality benchmarks (EQB) for protection of surface waters, sediments, and aquatic life were published as a special issue in Environmental Science and Pollution Research (Leung et al. 2014). Building on this successful foundation, the 2 nd International Conference on Deriving Environmental Quality Standards for the Protection of Aquatic Ecosystems (EQSPAE-2016) was held at HKU in June 2016.

With the conference grant from the Environment and Conservation Fund of the Hong Kong Special Administrative Region Government, we were able to bring leading experts in the field of derivation and application of EQBs from North America, Europe, Australia, Korea, and mainland China to further explore new and improved methods for advancing the science supporting national and international regulatory policies aimed at environmental protection. The EQSPAE-2016 Conference provided an invaluable platform for 128 environmental scientists and practitioners from 17 countries representing the academic, business, and governmental communities to participate in two 1-day training workshops and a 2-day scientific symposium and share their knowledge and experience in EQB derivation and water quality management and, importantly, to promote capacity building and foster international collaboration (Fig. 1).

In recent years, the Asia-Pacific region and countries such as Australia, Canada, China, Hong Kong, Korea, UK, and the USA have invested considerable efforts to revise and update surface water and sediment quality guidelines. This has prompted research and advancements in the science and several methodologies useful to the derivation of generic EQBs and site-specific EQBs, as well as advancements in related regulatory policies and applications for water quality management in different parts of the world.

Following on from the EQSPAE-2011 Conference, one of the pre-eminent leaders in this field, Dr. Peter Chapman, cautioned experts and policy-makers working in these endeavors that EQBs such as surface water and sediment quality guidelines represent only one of line of evidence for assessing the potential harm posed by chemicals and other stressors in the environment (Chapman 2017). EQBs, Dr. Chapman observed, are useful but not perfect tools for environmental

Responsible editor: Philippe Garrigues

Kenneth M. Y. Leung

kmyleung@hku.hk

Graham Merrington

graham.merrington@wca-environment.com

Michael St. J. Warne

michael.warne@coventry.ac.uk

Richard J. Wenning

rjwenning@ramboll.com

Fengchang $\mathrm{Wu}$

wufengchang@vip.skleg.cn
1 The Swire Institute of Marine Science and School of Biological Sciences, The University of Hong Kong, Pokfulam, Hong Kong, China

2 WCA Environment Limited, Brunel House Volunteer Way, Faringdon, Oxfordshire SN7 7YR, UK

3 Centre for Agroecology, Water and Resilience, Coventry University, Ryton Gardens, Wolston Lane, Coventry CV8 3LG, UK

4 Ramboll, 136 Commercial Street, Portland, ME 04101, USA

5 State Key Laboratory of Environmental Criteria and Risk Assessment and State Environmental Protection Key Laboratory of Lake Pollution Control, Chinese Research Academy of Environmental Sciences, Beijing, China 


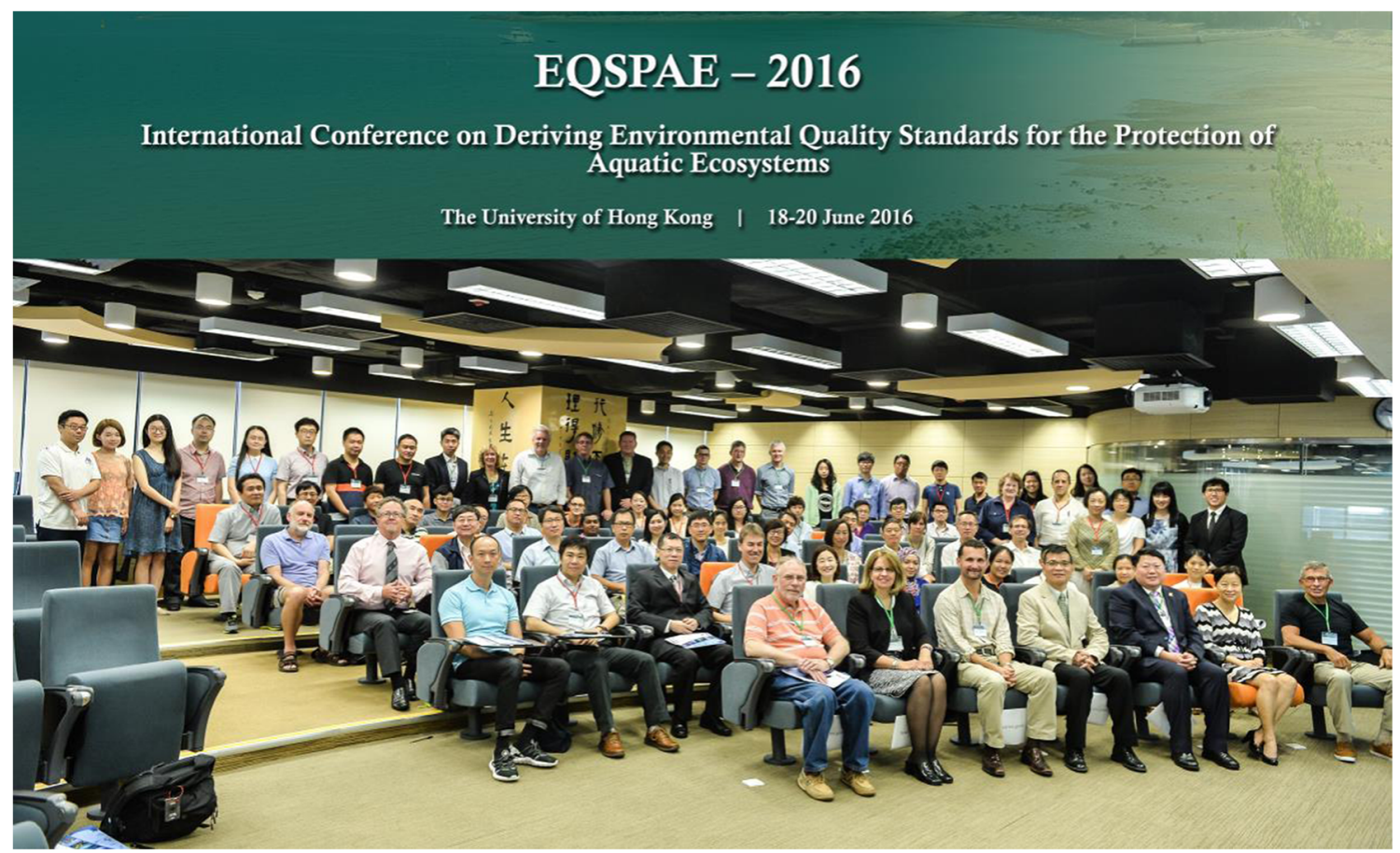

Fig. 1 Group picture taken after the opening ceremony of the EQSPAE-2016

decision-making. EQBs can be "good" in specific applications and a means to communicate scientific information to decision-makers, but EQBs can also be "bad" when adopted as absolute limits or aimed at the protection of individual organisms rather than populations of organisms or "ugly" when derived from overly simplistic indices or applied outside the bounds of scientific support.

Building on Dr. Chapman's caution and his inspiring keynote address, the EQSPAE-2016 Conference resolved to identify and explore a number of challenging science and regulatory issues that environmental scientists and policy-makers must overcome to be successful:

- How can we modify the current EQBs of chemical pollutants while considering the, as yet uncertain, combined effects of chemicals and climate change (e.g., temperature and $\mathrm{pH}$ changes) to aquatic life?

- How can we derive and apply appropriate EQBs of individual chemical pollutants when we are, in practice, required to manage chemical mixtures and multiple stressors in the aquatic environment?

- How can we make use of toxicity information from nonnative species to protect locally untested indigenous species?

- How can we make use of toxicity information from temperate regions to protect tropical, sub-tropical and polar aquatic ecosystems?

- What are the best approaches to design and conduct field experiments to validate the effectiveness of EQBs for protecting biodiversity and ecosystem function/service?
- How can we increase ecological realism in the scientific derivation of EQBs?

The scientific debates and discussions during the EQSPAE-2016 training workshops and symposia were both inspiring and spirited largely by the challenging questions posed by Dr. Chapman throughout the conference. It is with profound sadness that we acknowledge Dr. Chapman's passionate voice and wisdom will be missing as we continue to explore the answers to these and other challenging questions. Dr. Peter Michael Chapman (1951-2017) passed away, far too early, on 26 September 2017 leaving behind a devoted and loving family and countless friends and colleagues around the world.

As a global leader in the scientific derivation and application of EQBs and marine ecotoxicology, Dr. Chapman was the invited keynote speaker at both EQSPAE-2011 and EQSPAE2016 (Fig. 2). At the first conference, his keynote address, "Environmental Quality Guidelines and Protection of Ecosystem Services" highlighted the limitations of the general EQB framework and offered recommendations for improving the protection of aquatic life and defining management goals aimed at preserving ecosystem services. At EQSPAE-2016, Dr. Chapman's keynote address focused on "Environmental Quality Benchmarks-The Good, The Bad, The Ugly" (Chapman 2017).

Dr. Chapman's presence at the EQSPAE meetings was unmistakable; he never failed to ask sharply focused questions during the question-and-answer session after each 
Fig. 2 The late Dr. Peter Chapman presenting his opening keynote lecture at the EQSPAE2011 (a) and at the conference dinner at the EQSPAE-2016 (b)
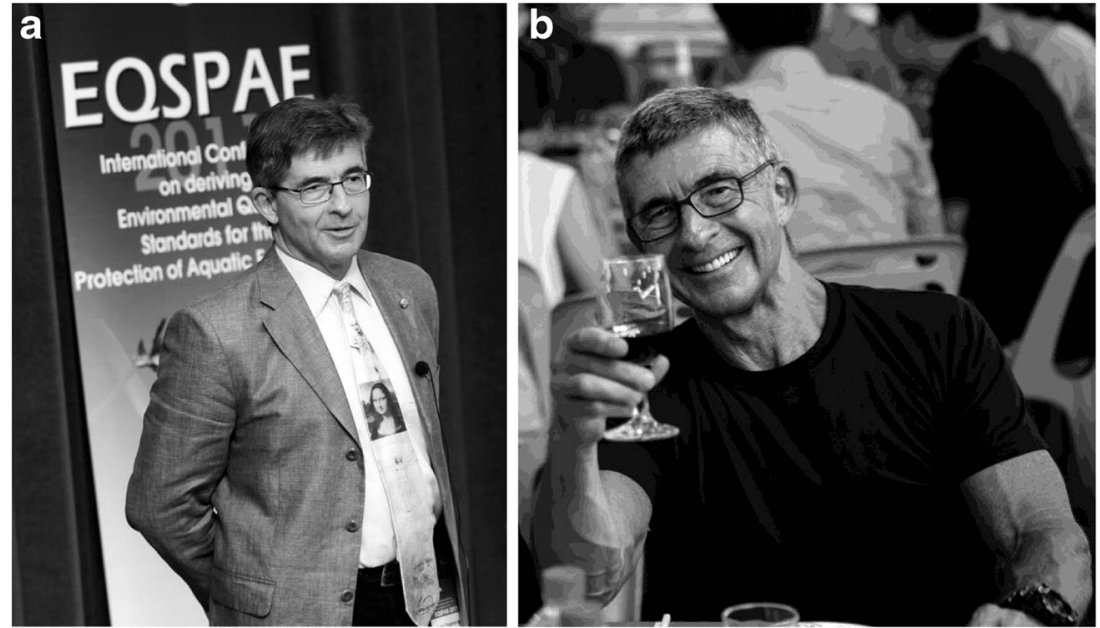

platform presentation and during round-table discussions. He shared his critical views unapologetically on a range of science and management issues, always supported by real-world examples to illustrate his views. He was provocative and passionate in promoting best practices in the field. Dr. Chapman was among the first scientists, if not the first, to advocate abolishing the use of no observed effect concentration (NOEC) data (Chapman et al. 1996). His arguments at EQSPAE-2011 for dropping the word "heavy" when referring to metal substances in the environment were convincing and unassailable (Chapman 2012).

Dr. Chapman's devotion to his profession was as boundless as his commitment to the EQSPAE meetings. He earned his PhD in benthic ecology in 1979 at the University of Victoria in Canada, with an emphasis on ecotoxicology and risk assessment. He was a partner for 25 years at EVS Environment Consultants in nearby Vancouver, among the earliest science-focused environmental consulting companies in North America and an inspiration for several successful environment professionals and ecology/risk consulting companies thereafter. His company merged with Golder Associates, and 10 years later, he retired to his private consulting practice, Chapema Environmental Strategies, in 2014. His many science and consulting collaborations never slowed down. From his early career, he devoted much of his effort and time to scientific writing and publishing in peer-reviewed journals (e.g., Environmental Science and Technology Environmental Toxicology and Chemistry, Integrated Environmental Assessment and Management, Marine Pollution Bulletin etc.). He served as editors for several science journals and shared his opinions on contemporary issues in environmental science and management through editorial articles and conference presentations. By last count, Dr. Chapman had published over 300 journal articles, earning an h-index of 60 and garnering more than 12,000 citations (Google Scholar citations: https:// scholar.google.com/citations?user=V0_QgUoAAAAJ\&hl=zhTW, retrieved on 26 October 2017).
His most well-known and highly cited published works include methods for assessment of sediment contamination (and in particular, metals), development of a sediment quality triad framework, proposals for numerous sediment quality criteria, methods for using safety factors in ecological risk assessment, a weight of evidence approach to handle uncertainty in risk assessment, and methods for whole effluent toxicity testing.

Dr. Chapman's influence on environmental risk assessment and management is evident in many parts of the world. He travelled constantly to supervise ecology surveys, advise governments, meet with stakeholders engaged in difficult environmental problem-solving, and give lectures. He was a dedicated and committed supporter of university students and young environmental professionals. He never missed an opportunity to share his knowledge and experience with young people. We shall miss his voice, his passion, and his boundless energy and enthusiasm for making things right in science and promoting the protection of the natural environment.

As a way to pay tribute to his leadership and wonderful contributions to the advancement of the science and application of EQBs, the Organizing Committee of the EQSPAE2016 Conference and our guest editorial team dedicate this special issue to Dr. Peter Chapman. He was our brilliant and gifted colleague, our favorite critic, and most of all, our dear and generous, kind-hearted friend who was always ready with a wry smile and the time to listen and share considered opinions. We shall miss him dearly.

\section{Papers in this special issue}

This special issue of Environmental Science and Pollution Research is entitled "Environmental Quality Benchmarks for Aquatic Ecosystem Protection: Derivation and Application." It features a collection of 15 papers presented by experts at the 
EQSPAE-2016 Conference. Following the opening article by Dr. Peter Chapman on the good, the bad, and the ugly of EQBs, Professor Allen Burton discusses how we can establish more realistic sediment quality guidelines while considering the coexisting multiple stressors in the aquatic benthic ecosystem. Next, Dr. Graham Merrington and colleagues deliberate on why and how the use of EQBs should result in environmental benefits. Since manufactured nanomaterials, as an emerging group of chemical contaminants, currently do not have EQBs, Mr. Racliffe Lai and his team discuss the challenges and suggest possible approaches for setting EQBs to protect aquatic life.

Thereafter, this special issue presents seven papers describing the current status and latest advancements on the derivation and application of EQBs in China (Zhao et al.; Chen et al.), Korea (Kwak et al.; Kwak and An), Switzerland (Casado-Martinez et al.), the USA (Saari et al.), and Australia (Warne et al.), respectively. This special issue concludes with four papers addressing contemporary issues related to laboratory-based toxicity tests, including the use of the water-effect ratio to develop site-species EQBs for copper (Bao et al.), some insights from multigenerational toxicity tests with marine copepods (Sun et al.), and revealing toxicities of some emerging chemicals (Ali et al.; Lei et al.). We feel strongly that this collection of papers from the EQSPAE-2016 Conference are valuable contributions to the scientific literature and useful to environmental researchers and practitioners worldwide involved in management of surface water and sediment quality.

Acknowledgements We are grateful to all of the sponsors of the EQSPAE-2016 Conference including the Environment and Conservation Fund (project no. ECF 2015-40) of the Hong Kong SAR Government; the School of Biological Sciences, HKU; the State Key Laboratory in Marine Pollution, City University of Hong Kong; and the Society of Environmental Toxicology and Chemistry (SETAC) Asia Pacific Geographic Unit. Finally, we specially thank the Editor-in-Chief of ESPR, Prof. Philippe Garrigues and his Editorial Assistants, Géraldine Billerot, Fanny Creusot, and Florence Delavaud for their tremendous support and assistance throughout the production process of this special issue. All authors contributing to this special issue are greatly appreciated. Finally, we specially thank Ms. Helen Leung, Ms. Tracy Wong, Ms. Esther Liu, Ms. Katie Yeung, Mr. Racliffe Lai, and other student helpers for making the EQSPAE-2016 Conference such a success.

\section{References}

Chapman PM (2012) "Heavy metal" — cacophony, not symphony. Integr Environ Assess Manag 8(2):216. https://doi.org/10.1002/ieam.1289

Chapman, P.M. (2017) Environmental quality benchmarks - the good, the bad, the ugly. Environ Sci Pollut Res, https://doi.org/10.1007/ s11356-016-7924-2

Chapman PM, Caldwell RS, Chapman PF (1996) A warning: NOECs are inappropriate for regulatory use. Environ Toxicol Chem 15(2):7779. https://doi.org/10.1002/etc.5620150201
Leung KMY, Merrington G, Warne MSJ, Wenning RJ (eds) (2014) Environmental quality benchmarks for protecting aquatic ecosystems. Environ Sci Pollut Res 21(1):1-243. https://doi.org/10.1007/ s11356-013-1996-Z

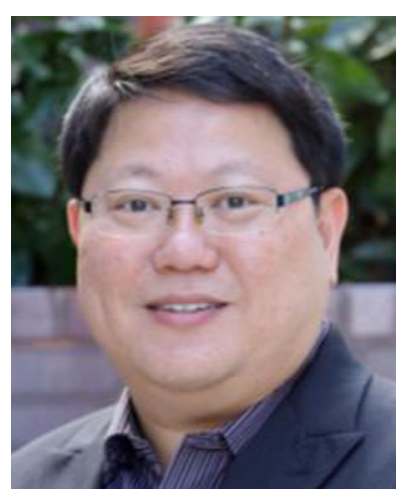

Professor Kenneth M. Y. Leung is a Professor of Aquatic Ecology and Toxicology at the Swire Institute of Marine Science and School of Biological Sciences in the University of Hong Kong. He obtained his $\mathrm{PhD}$ in marine ecotoxicology from University of Glasgow and received postdoctoral training in environmental risk assessment of chemical contaminants at University of London. So far, he has edited six volumes of conference proceedings and published over 175 peer-reviewed articles which are principally related to ecology, pollution, ecotoxicology, and environmental risk assessment in both marine and freshwater ecosystems. Professor Leung has also made contributions to the development of marine water quality objectives in Hong Kong and is currently collaborating with the Chinese Research Academy of Environmental Sciences to refine the water quality criteria system in China. He is an Editor-in-Chief of Regional Studies in Marine Science and an Associate Editor of Environmental Science and Pollution Research and Integrated Environmental Assessment and Management. During 2010-2012, he was the elected President of the Society of Environmental Toxicology and Chemistry (SETAC) Asia Pacific Geographic Unit. Currently, he serves as the Chairman of the Marine Parks Committee and Marine Mammal Conservation Working Group, as well as a member of the Advisory Council on the Environment, and Advisory Council on Food and Environmental Hygiene for the Government of the Hong Kong Special Administrative Region. Owing to his professional achievements and community services, he was selected as one of the "Ten Outstanding Young Persons" in Hong Kong by Junior Chamber International in 2010. In 2017, Professor Leung was conferred with two prestigious awards, including the "19th Biwako Prize for Ecology" by the Ecological Society of Japan and the "SETAC Fellows Award" by SETAC.

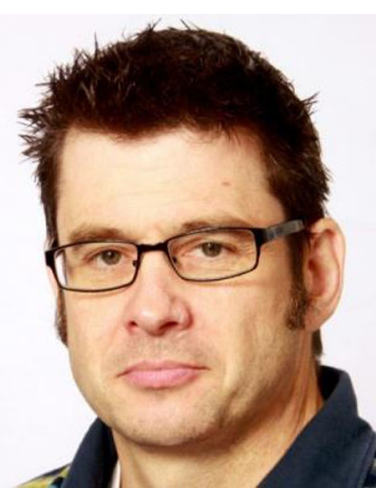

Dr. Graham Merrington is the Managing Director of WCA. He has more than a 25 -year experience of terrestrial risk assessment, waste regulation, and the fate, behaviour and effects of trace elements, and other inorganic contaminants in the environment. After working as an academic in the UK and Australia, Graham joined the Environment Agency of England and Wales where for 5 years, he led an R\&D Programme focused on Environmental Quality Standards (EQS) in soils, waters, and sediments. Key projects included the incorporation of Biotic Ligand Models into compliance assessment for regulators, the implementation and use of ecologically based soil standards for metals, and the derivation of soil quality indicators to assess sustainable land management. He has also represented the UK at Expert Groups for 
the WFD and was a regular attendee as an expert for metal-related issues at European Commission TCNES. Graham has written or co-authored more than 50 scientific publications focussing on the behaviour and fate of metals in terrestrial and aquatic systems. More recently he has written EU guidance on the regulatory implementation of bioavailability-based EQS for metals and led on drafting the guidance for the implementation of $\mathrm{EQS}_{\text {biota. }}$

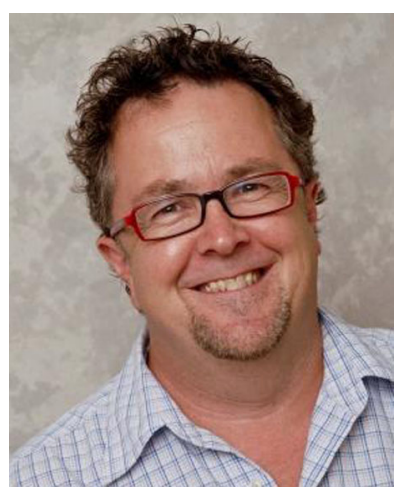

Professor Michael Warne is a Professor of Ecotoxicology and Water Quality at the Centre for Agroecology, Water and Resilience, Coventry University, United Kingdom. He holds honorary positions at the University of Queensland, Griffith University, and the Queensland Department of Science and Environment in Australia. Prior to his current position, he has worked in academia, government, and research organizations. He has extensive research experience in aquatic and terrestrial ecotoxicology and in the derivation of environmental quality guidelines. He was a key author of the Australian and New Zealand Water Quality Guidelines (2000) for toxicants. He is also a key author of the current revision of these guidelines and led the team that derived guideline values for over 20 new pesticides. In addition, he derived the Australian Soil Quality Guidelines for toxicants in contaminated sites and the Australian limits for metals in soil amendments (i.e., biosolids and mineral fertilisers) and industrial wastes applied to agricultural land. His research interests are on the transport, fate, and effects of contaminants from agricultural land to aquatic ecosystems, any form of organic chemical contamination, effects of multiple stressors including mixtures of chemicals, derivation of EQBs, and risk assessment. Professor Warne has written or co-authored over 110 peer-reviewed articles. He has been a member of the Editorial Boards of Integrated Environmental Assessment and Management and Environmental Toxicology and Chemistry.

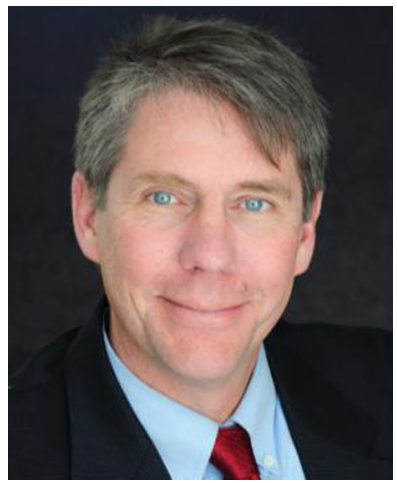

Mr. Richard J. Wenning is a Principal Scientist at Ramboll and the leader for the company's Ecology Services practice. He has 30 years of experience in ecotoxicology, human and ecological risk assessment, and the investigation, assessment, and restoration of contaminated waterways and industrial ports/harbors. He has considerable expertise in the environmental fate and ecotoxicity of contaminants and derivation of sediment quality objectives in estuarine, riverine, and marine aquatic environments. He has directed teams of engineers and scientists dedicated to contaminated sediment remediation and rehabilitation of the aquatic environment in Australia, the Asia-Pacific region, Europe, and North and South America. Mr. Wenning has served on expert review panels addressing sediment management and risk assessment in several countries and has published extensively in the scientific literature on chemical source fingerprinting, contaminated sediments, and risk assessment. Mr. Wenning is a co-editor of the book Use of Sediment Quality Guidelines and Related Tools for the Assessment of Contaminated Sediments (2005; SETAC Press), and two books on Environmental Security in Harbours and Coastal Areas (2007, 2009; Springer). Since 2004, Mr. Wenning serves as the Editor-in-Chief of the Society of Environmental Toxicology and Chemistry (SETAC) peer-reviewed international journal, Integrated Environmental Assessment and Management.

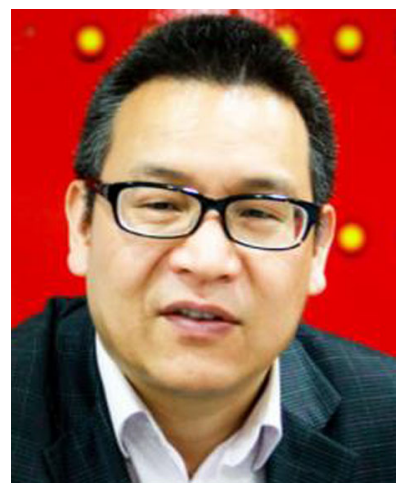

Professor Fengchang $\mathrm{Wu}$ is a Professor of Ecotoxicology and Biogeochemistry and Director at the State Key Laboratory of Environmental Criteria and Risk Assessment, Chinese Research Academy of Environmental Sciences of Ministry of Environmental Protection, China, and a Member of the Chinese Academy of Engineering. He obtained his $\mathrm{PhD}$ in biogeochemistry from Chinese Academy of Sciences and received further trainings in water quality and environmental risk assessment at McMaster University, Trent University, and Nagoya University. So far, he has published over 300 peer-reviewed articles which are principally related to water quality criteria and standard, biogeochemistry, ecotoxicology, and risk assessment in freshwater ecosystems. He is an associate editor of four international journals, namely Environmental Management, Asian Journal of Ecotoxicology, Environmental Toxicology and Chemistry, and Integrated Environmental Assessment and Management. Owing to his professional achievements, Professor $\mathrm{Wu}$ was conferred with several prestigious awards, including Second Runner-Up Best Science Article of the journal Environmental Science and Technology (2012), the Prize for Scientific and Technological Progress from Ho Leung Ho Lee Foundation, Hong Kong (2014), the Government Service Award (2015) by the Society of Environmental Toxicology and Chemistry (SETAC), and two National Science and Technology Progress Awards by the Government of the People's Republic of China. 